Case Report

\title{
FATAL SNAKE BITE IN A BROWN BEAR (Ursus arctos L.): A CASE REPORT
}

\author{
Romel Velev ${ }^{1}$, Toni Tankoski², Maja Tankoska² \\ ${ }^{1}$ Department of Pharmacology and Toxicology, Faculty of Veterinary Medicine - Skopje, \\ "Ss. Cyril and Methodius" University in Skopje, R. Macedonia \\ ${ }^{2}$ Veterinary Practice Toni, Makedonski Prosvetiteli b.b., T.C. Ohrigjanka lok. 1, \\ 6000 Ohrid, R. Macedonia
}

Received 2 August 2014; Received in revised form 30 October 2014; Accepted 26 November 2014

\begin{abstract}
Poisoning from snake venom in animals is an emergency which requires immediate attention or otherwise, the delayed and inadequate treatment leads to untoward consequences and death. The present paper describes a case of venomous snakebite in a brown bear cub (Ursus arctos L.) and its therapeutic management. The brown bear cub of which was found alone on the slopes of a mountain in the southwest part of the country was presented to the peripheral veterinary practice in Ohrid with a history of dullness, disorientation and excessive swelling around the left forepaw. It was diagnosed for snakebite based on the history and physical examination. The hematological parameters showed reduced values of hemoglobin, packed cell volume and increased total leukocyte count. The biochemical values showed elevated levels of alanine aminotransferase and creatinine. After immobilization of the animal, the treatment was conducted with fluids, corticosteroid and broad spectrum antibiotic with careful monitoring. Despite the treatment which was initiated immediately, it was only partially effective, and the animal died one hour after the beginning of its course. Poisonous snakes are common in the mountainous part of Macedonia and, just like humans, wild bears especially their cubs are susceptible to the deadly venom of some species. The severity of the reaction to snake venom and prognosis in animals depends on a number of factors: on the type and species of snake, on how much venom was injected, on the location of the bite, on the age, health and body weight of the animal and crucially, the time interval between the snakebite and the application of the treatment.
\end{abstract}

Key words: venomous snakebite, brown bear (Ursus arctos L.), treatment

\section{INTRODUCTION}

Generally, snakes are harmless and play an important environmental role in the fragile ecosystems of the nation's wildlife areas. They usually use camouflage and methods like hissing and biting. Despite the fact that many of them are non-venomous, a few of them are venomous. In Macedonia there are three venomous species of snakes (1): Vipera ammodytes L. (Macedonian: poskok, kamenjarka); Vipera berus L. (Macedonian:

Corresponding author: Prof. Romel Velev, PhD

E-mail address: vromel@fvm.ukim.edu.mk

Present address: Ss. Cyril and Methodius University in Skopje

Faculty of Veterinary Medicine - Skopje

Department of Pharmacology and Toxicology

Lazar Pop-Trajkov 5-7 1000, Skopje, Macedonia

Phone: ++38923240 768

Copyright: (C) 2015 Velev R. This is an open-access article published under the terms of the Creative Commons Attribution License which permits unrestricted use, distribution, and reproduction in any medium, provided the original author and source are credited.

Competing Interests: The authors have declared that no competing interests exist.

Available Online First: 3 December 2014

http://dx.doi.org/10.14432/j.macvetrev.2014.12.034 sharka, lutica, osojnica) and Vipera ursinii $L$. (Macedonian: ostroglava sharka, ostroglava osojnica, stepska lutica). Most accidental bites usually occur whenever a snake is encountered and does not have time or space to slip away. In Macedonia, most of the cases of snakebite in animals have been reported in dogs, goats and horses. Snakebites can be serious, especially in young animals that get bit multiple times. Poisonous snakes are common in the mountainous part of Macedonia and, just like humans, wild bears, especially their cubs, are susceptible to the deadly venom of some species.

The brown bear (Ursus arctos L.) is the largest of the carnivore species found in the Republic of Macedonia. They belong to the same nominal subspecies as the whole European brown bear population. Today, their population is restricted to the mountainous forest areas in the western, central and southern parts of the country. It occupies the slopes of Shara Mountain, Korab, Bistra, Stogovo, Karaorman, Jablanica, Plaknenski Planini, Galichica and Baba Mountain (2). The current population 
estimates vary between 160-200 brown bears (3). Both the restricted distribution and the decline of the population are a result of intensive hunting, destruction and fragmentation of the bear's habitat and other disturbances by humans.

Poisoning from snake venom in animals is an emergency which requires immediate attention or otherwise, the delayed and inadequate treatment leads to untoward consequences. The present paper describes a case of a venomous snakebite in a brown bear cub and its therapeutic management.

\section{CASE HISTORY AND OBSERVATION}

In the beginning of May, 2014, a male brown bear cub (2 - 3 months of age), weighing about $7-10 \mathrm{~kg}$, was presented to the peripheral veterinary practice in the city of Ohrid with a history of dullness, disorientation, depression, and in a recumbent position (Fig.1 and Fig. 2). According to the onlookers, the teddy bear was found alone on the slopes of Slavej Planina near the Karaorman mountain in the southwest part of the country. Its left forepaw was swollen and bleeding in the front region (Fig. 4). by an unidentified venomous snake. The clinical parameters like rectal temperature, capillary refill time (CRT), pulse and respiratory rate showed $36.0^{\circ} \mathrm{C}$ (normal range: $37.0-37.5^{\circ} \mathrm{C}$ ), CRT $>2$ sec., 50 heart beats per min. (normal range in adult bear: $40-50 / \mathrm{min}$ ) and 20 respirations per min. (normal range: $15-30 / \mathrm{min}$ ) (4). Further examination revealed almost white gums, weak pulse, presence of cold extremities, reduced reflexes, unfocused eyes which appear to glaze over and an apparent depressed "mental" state.

The blood samples were collected with and without ethylene diamine tetra acetic acid (EDTA) for hematological parameters like hemoglobin, packed cell volume and total leukocyte count estimation and biochemical parameters such as alanine aminotransferase and creatinin estimation. The hematological parameters revealed decreased hemoglobin concentration $(12.6 \mathrm{~g} / \mathrm{dl}$ ) (normal range: $14.0-20.0 \mathrm{~g} / \mathrm{dl}$ ) and packed cell volume (35\%) (Normal range: $42-63.0 \%$ ) and increased total leukocyte count $(18000 / \mathrm{ml})$ (normal range: 7000 - 12000/ml) (5). The biochemical values showed elevated levels of alanine aminotransferase (62 IU/dl) (normal range: $10-49 \mathrm{IU} / \mathrm{dl}$ ) and creatinine $(2.2 \mathrm{mg} / \mathrm{dl})$ (normal range: $0.5-2.0 \mathrm{mg} / \mathrm{dl})(6)$.
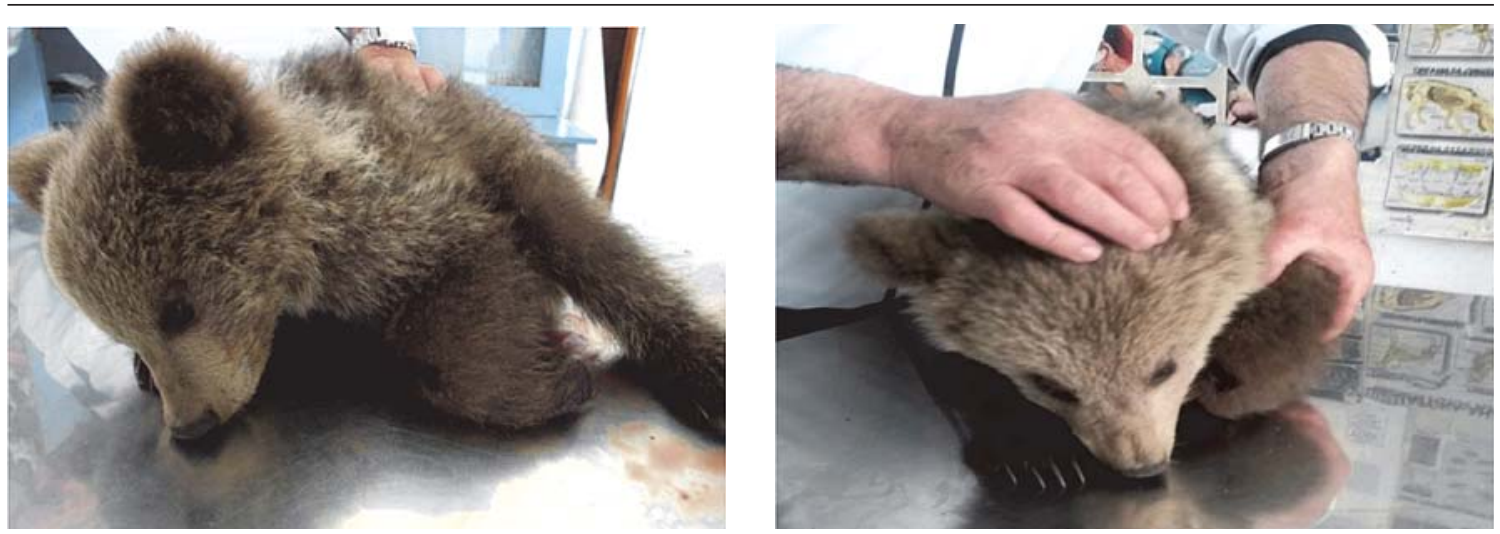

Figure 1 (left) and Figure 2 (right). Brown bear cub (Ursus arctos L.) in an apparent depressed mental state and in a recumbent position

\section{DIAGNOSIS}

The physical examination of the bear revealed a markedly discolored swollen area on the left forepaw. The hairs of the fur hide the typical fang marks of a snakebite. A marked increase in volume around the left forepaw, extending to the region of the shoulder and bleeding (dark bloody fluid which oozes from the wound) was also noticed (Fig. 3 and Fig. 4). Bleeding was also easily observed through the perforation left by the needles used for blood collection and drug administration.

Based on the history and physical examination of the bear, the case was suspected for snakebite 114

\section{TREATMENT}

The snakebite site was shaved, and the wound cleaned thoroughly with germicidal soap. Once immobilized, the animal received $300 \mathrm{~mL}$ Ringer's lactate solution (Lactated Ringers injection, Vioser) and $15 \mathrm{~mL}$ hetastarch $6 \%$ (Voluven $6 \%$, Fresenius Kabi) intravenously, $10.0 \mathrm{mg}$ dexamethazone (Colvasone $0.2 \%$, Norbrook) also intravenously, and $250 \mathrm{mg}$ procaine benzyl penicillin and $250 \mathrm{mg}$ dihydrostreptomycin sulfate (Sustrepen, Genera) subcutaneously (14). Since the snake fangs can be contaminated with different types of bacteria, we administrated subcutaneously the combination 


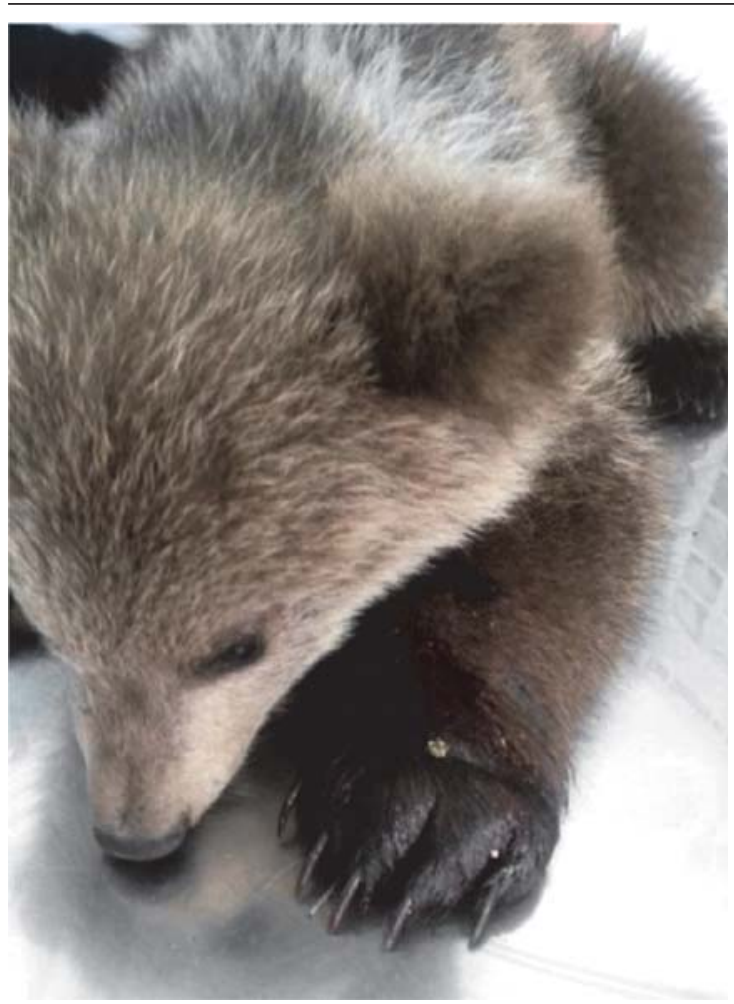

Figure 3. Increased size of the left forepaw

of procaine benzyl penicillin and $250 \mathrm{mg}$ dihydrostreptomycin sulfate (Sustrepen, Genera) to expand the spectrum of antibiotics. Then the animal was kept under observation, but the clinical symptoms worsened. Despite the treatment which was initiated immediately, it was only partially effective, and the animal died one hour after the beginning of the course of the treatment. The bear was not treated with specific anti-snake venom. The private practice in Ohrid at that moment did not possess snake antivenin, which in Macedonia is permitted to be possessed and applied only by human medical institutions. It may be available only on an as-needed basis through a larger human hospital/outpatient emergency room. The clinical condition and the time required to supply snake antivenin did not permit for the animal to be treated specifically.

Necropsy of the animal was done the next day by an authorized veterinary inspector who conducted the postmortem protocol and confirmed a venomous snakebite of the brown bear cub. At necropsy, an area of hemorrhagic edema was found around the left front paw that reached the subcutaneous tissue. The liver presented congestion, mainly centrilobular. In the lung, there were areas of congestion. The other organs did not show significant alterations.

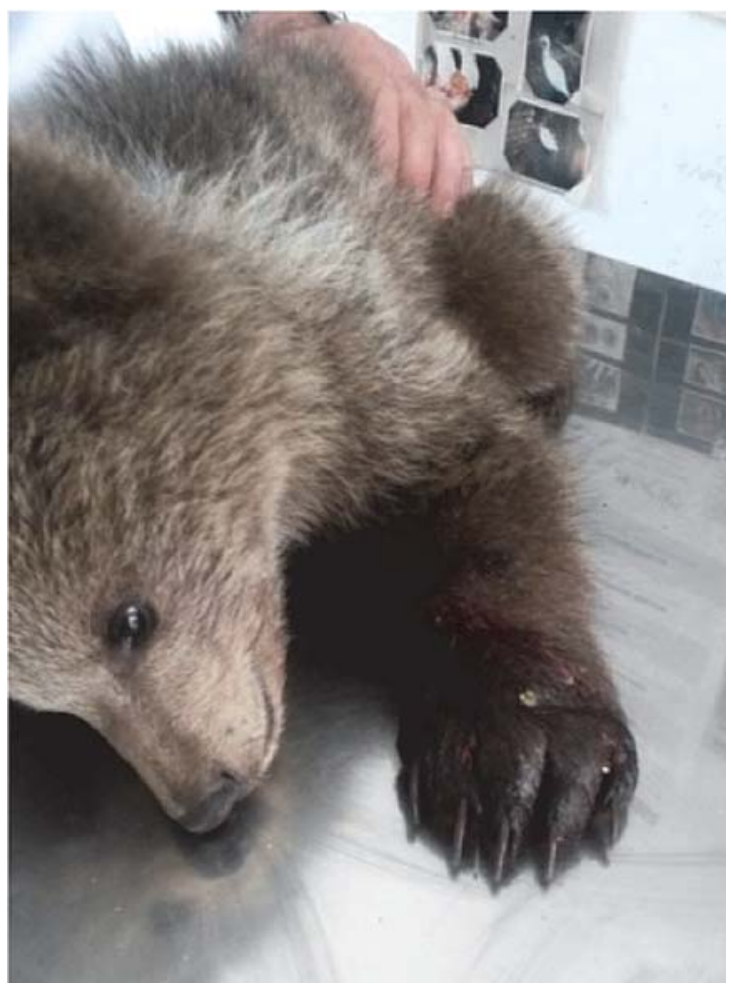

Figure 4. Dark bloody fluid which oozes from the wound

\section{DISCUSSION}

Snakebite presents as a minor mechanical trauma, allergy to venom (rare) and an evenomation syndrome. Three main clinical envenomation syndromes in snakebite should be identified: painful progressive swelling, progressive weakness and bleeding. Snake venoms are complex mixture of proteins and peptides, consisting of both enzymatic and non enzymatic compounds. The other components of snake venoms are glycoproteins, lipids, and biogenic amines, such as histamine, serotonin and neurotransmitters (catecholamines and acetylcholine) (7). Snakes venoms are often characterized as either hemotoxic (those that have hemorrhagic effects; traditionally associated with vipers from family Viperidae) or neurotoxic (those that produce paralysis and death by respiratory shock; traditionally associated with elapids from family Elapidae); many venoms, such as those from some rattlesnakes, show evidence of both types of effects $(8,9)$. While the term hemotoxic implies effects only to the circulatory system, hemotoxic venoms often cause tissue destruction in other body systems (9). Most of these tissue destructive properties are attributed to proteins and digestive enzymes such as phospholipase A2 which are commonly present in venom (9). 
In our case, the cyanotic edema observed at the site of the bite may be attributed to enzyme hyaluronidase which acts as a spreading factor. Hyalurinadase cleaves internal glycoside bonds in certain acid mucopolysaccharides resulting in decreased viscosity of connective tissues, allowing other fractions of venom to penetrate the tissues (7). The increased size of the affected paw, is probably due to local inflammation. Snake venom has proteolytic activity, which is believed to be responsible for the inflammation (8). It is important to notice that although the bite was on the paw, the animal developed systemic problems and died. Haemotoxic effect of snake venom may interfere with many components of the haemostatic system (10). Moreover, the toxins such as the haemorrhagins cause spontaneous bleeding in the gingival sulci, nose, skin and gastrointestinal tract (11). However, bleeding tendencies were not noticed in our case. The decrease of hematocrit and hemoglobin levels in our case may be attributed to damage of the blood cells by the snake venom. The increased biochemical values like alanine aminotransferase and creatinine may be due to the hepatotoxic and nephrotoxic effect of snake venom (12).

Generally, the therapy for snakebite is comprised of, the first aid, antivenin, fluid therapy, anti-inflammatory agents and antibiotics. First aid measures which attempt to denature the venom (topical applications, electrotherapy, cryotherapy), remove the venom (incision and suction, excision) or retard its absorption (various types of tourniquet, cryotherapy) have not proved effective in controlled studies and can be potentially harmful. Therefore, syndromic management of snakebite without knowing the species of the snake is logical and effective.

Treatment for viper envenomation should be directed toward preventing or controlling shock, neutralizing venom, preventing or controlling coagulopathy, minimizing necrosis, and preventing secondary infection. Any animal presented within $24 \mathrm{hr}$ of a snakebite showing signs of vipers envenomation requires intensive treatment, starting with IV crystalloids to combat hypotension. Hetastarch may be helpful to manage hypovolemia; however, colloids should be used with caution because of their potential to leak out of damaged vessels and pull fluids into tissue beds. Rapidacting corticosteroids may be of benefit in the first $24 \mathrm{hr}$ to help control shock, protect against tissue damage, and minimize the likelihood of allergic reactions to antivenin. However, prolonged use of corticosteroids is not recommended (13).

Antivenom is the only direct and specific means of neutralizing snake venom. Animals bitten by a viperine snake in Macedonia may be treated with 116 antivenin, which may be available on an as-needed basis through larger human hospital emergency rooms. A polyvalent antivenin (Viekvin ${ }^{\circledR}$ equineorigin polyvalent $\mathrm{F}(\mathrm{ab})^{2}$ fragment antivenin Institute Torlak) against European vipers (Vipera ammodytes and Vipera berus) is available in Macedonia and should be used in all cases of substantial snake envenomation, if is not too late.

It is most effective if administered in the first $6 \mathrm{hr}$ after the bite. The efficacy of antivenin is diminished if the bite occurred $>24 \mathrm{hr}$ previously. Because of the cost, usually its use is generally reserved for small and young animals, animals that have received multiple bites, and/or animals that are showing signs of shock. In severe envenomations, multiple vials of antivenin may be required, although this is frequently cost-prohibitive in veterinary patients. In our case, clinical condition and the time required to supply snake antivenin has not permitted for the animal to be treated specifically.

Several potential pathogens, including Pseudomonas aeruginosa, Clostridium spp, Corynebacterium spp, and staphylococci have been isolated from the mouth of snakes. However, the incidence of wound infection after snake bites is low, and many clinicians use broad-spectrum antibiotics only when significant tissue necrosis is present (13).

\section{CONCLUSION}

This paper describes for the first time a case of venomous snakebite of a brown bear cub in Macedonia and provides details of the treatment of this endangered wild animal. Snakebite in animals, with envenomation, is a true emergency. Rapid examination and appropriate treatment are paramount. Intensive therapy should be instituted as soon as possible, because irreversible effects of venom begin immediately after envenomation. Unfortunately, the severity of the reaction to the snake venom and prognosis in animals depends on a number of factors: on the type and species of snake, on how much venom was injected, on the location of the bite, on the age, health and body weight of the animal and crucially the time interval between the snakebite and the application of treatment. Mortality is generally higher from bites to the thorax or abdomen than from bites to the extremities. However, this may relate to the size and vulnerability of the victim. In our case, it is important to notice that although the bite was on the paw, the animal developed systemic problems and died because it was found, delivered and treated 
too late. Animals bitten by a viperine snake may be treated with antivenin, but the problem is that they are available only on an as-needed basis through larger human hospital emergency rooms. The provided case report should be used as a baseline reference for venomous snakebite treatment in the species, especially in scenarios where individual animals are of significant value to conservation efforts.

\section{REFERENCES}

1. List of snakes in the Republic of Macedonia: http:// en.wikipedia.org /wiki/ List of snakes in the_Republic_of_Macedonia

2. Stojanovski, L., Arsovska, S. (1996). Report on the Status of the brown bear (Ursus arctos L. 1758) in the Republic of Macedonia.

3. Melovski, L., Godes, C. (2002). Large carnivores in the "Republic of Macedonia" In Psaroudas, S. (Ed.), Protected areas in the Southern Balkans - Legislation, large carnivores, transborder areas. (pp. 81-93). Thessaloniki, Greece

4. Detailed physiology notes with literature reports for the Brown bear - Ursus arctos.

http://wildpro.twycrosszoo.org/S/0MCarnivor/ursidae/ ursus/Ursus_arctos/10Ursus_arctosDetPhy.htm

5. Pearson, A.M., Halloran, D.W. (1972). Hematology of the brown bear (Ursus arctos) from southwestern Yukon Territory, Canada. Canadian Journal of Zoology 50(3): 279-286.

http://dx.doi.org/10.1139/z72-038

PMid:5014061
6. Kuntze, A., Hundsdorf, P. (1985). Haematological and biochemical parameters of clinically intact and pathologically affected polar bears (Thalarctos maritimus) and brown bears (Ursus arctos). Verhandlungsbericht des 27. Internationalen Symposiums über die Erkrankungen der Zootiere (pp. 385-391). 9-13 June 1985, St Vincent/Torino, Akademie-Verlag Berlin

7. Klaassen, C.D. (2008). Properties and toxicities of animal venoms. In McGraw-Hill (Ed.), Toxicology $7^{\text {th }}$ Ed. (pp 1093-1098). New Delhi

8. Jiminez-Porras, J.M. (1968). Pharmacology of peptides and proteins in snake venoms. Annual Review of Pharmacology 8, 299-318.

http://dx.doi.org/10.1146/annurev.pa.08.040168.001503 PMid:4875394

9. Greene, H.W. (1997). Snakes: The evolution of mystery in nature. Berkeley, California: University of Berkeley Press

10. Wolff, F. A. D. (2006). Natural toxins. In: Clarke's analysis of drugs and poison. Pharmaceutical press, London, Electronic Version

11. Warrell D. A., Fenner, P. J. (1993). Venomous bites and stings. Br. Med. Bull, 49, 423-439.

12. O'Shea, M. (2005). Venomous snakes of the world. Princeton: Princeton University Press

13. Overview of Snakebite. Snakebite: Merck Veterinary Manual

www. merckmanuals.com /vet/.../snakebite/overview of_snakebite.html

14. Velev, R., Krleska - Veleva, N. (2013). Practical use of registered veterinary medicinal products in Macedonia in identifying the risk of developing of antimicrobial resistance. Mac Vet Rev., 36(1): 5-12. 